
\title{
CARACTERIZAÇÃO DA MANIPUEIRA E POSSIBILIDADES DE
TRATAMENTO
}

\section{MANIPUEIRA CHARACTERIZATION AND TREATMENT POSSIBILITIES}

\author{
Igor Aparecido dos Santos Correia ${ }^{1}$; Nadine Caroline Bento Silva ${ }^{1}$; Alexandre \\ Teixeira de Souza ${ }^{1}$; Ana Paula Jambers Scandelai ${ }^{2}$ \\ ${ }^{1}$ Centro Universitário de Adamantina, Faculdade de Engenharia Ambiental, \\ Adamantina, SP. \\ E-mails: aparecidoigor@hotmail.com, nadinecarolina@hotmail.com, \\ alteiso@hotmail.com \\ ${ }^{2}$ Universidade Estadual de Maringá, Departamento de Engenharia Química, Maringá, \\ PR \\ e-mail: paulascandelai@hotmail.com
}

RESUMO - Devido à presença de elevada carga orgânica e ao ácido cianídrico, a manipueira, efluente da produção de mandioca, necessita de tratamento adequado antes de ser lançado no ambiente. $O$ presente estudo objetivou caracterizar a manipueira de uma indústria produtora de farinha e apresentar os possíveis sistemas de tratamento para a sua degradação. A caracterização da manipueira ocorreu pelos parâmetros de $\mathrm{pH}$, turbidez, demanda química e bioquímica de oxigênio, sólidos totais, sólidos totais fixos, sólidos totais voláteis e cianeto e cianeto. Todos os parâmetros avaliados se apresentaram elevados e acima dos limites permitidos pela legislação, evidenciando a necessidade de seu tratamento. A partir do levantamento de tratamentos biológicos e físico-químicos, ressalta-se que a escolha da combinação mais adequada irá depender, principalmente, das características da manipueira gerada, dos custos e das eficiências dos processos, e dos fatores legais.

Palavras-chave: mandioca; Manihot esculenta; cianeto.

ABSTRACT - Due to the presence of high organic load and hydrocyanic acid, manipueira, the effluent from cassava production, requires appropriate treatment before being discharge into the environment. This study aimed to characterize the manipueira of a flour producing industry and present possible treatment systems for its degradation. The manipueira characterization occurred by the parameters of $\mathrm{pH}$, turbidity, chemical and, biochemical oxygen demand, total solids, total fixed solids, total volatile solids and cyanide. All parameters evaluated were high and above the limits allowed by the legislation, evidencing the need for its treatment. From the survey of biological and physical-chemical treatments $\mathrm{s}$, it is emphasized that the choice of the most appropriate combination will depend mainly on the characteristics of the manipueira generated, the costs and the efficiencies process, and the legal factors.

Keywords: cassava; Manihot esculenta; cyanide. 


\section{INTRODUÇÃO}

Com o crescimento populacional, a demanda por alimentos tem aumentado cada vez mais. O ramo das indústrias de farinha ou as casas de fecularia estão em expansão, principalmente na região Nordeste do Brasil (INSTITUTO BRASILEIRO DE GEOGRÁFICA E ESTATÍSTICA, 2010), onde a matéria-prima das mesmas, a mandioca, é encontrada em abundância. Além disso, por ser um alimento que causa satisfação, a mandioca torna-se um meio de alimentação viável para alguns estados que possuem escassez de alimentos ou de recursos, territoriais e/ou financeiros.

Segundo o Serviço Brasileiro de Apoio às Micro e Pequenas Empresas - SEBRAE (2012), no Brasil, a região Norte apresenta a maior média de consumo de mandioca do país, com 23,54 kg per capita $^{-1}$ ano $^{-1}$, seguida da região Nordeste, que possui consumo médio de $9,67 \mathrm{~kg}$ per capita ${ }^{-1}$ $a^{-1}$, enquanto que as demais regiões não passam de um consumo de $1,3 \mathrm{~kg}$ per capita $^{-1}$ ano ${ }^{-1}$ cada.

A mandioca (Manihot esculenta Crantz) é um alimento com diversas utilidades, tanto para o uso culinário, quanto como matéria-prima para o uso industrial, podendo ser utilizada na fabricação de alimentos, na tecelagem e na indústria cosmética, dentre outros.

Ao produzir farinha, durante a prensagem da mandioca, as indústrias geram um efluente conhecido como manipueira, que significa "água de goma", da língua Tupi Guarani, devido à sua alta viscosidade. Este líquido é altamente poluente, pois possui elevada carga orgânica, ou seja, altas demandas químicas e bioquímicas de oxigênio (DQO e DBO, respectivamente).

Tanto a mandioca (antes do processamento), quanto a manipueira, contém ácido cianídrico ( $\mathrm{HCN})$, o qual é considerado venenoso e nocivo à alimentação humana e animal, uma vez que pode causar sérios danos ao sistema nervoso humano, provocando doenças degenerativas (JUBB E HUXTABLE, 1993).

Quando descartado de forma incorreta ou sem tratamento adequado, a manipueira pode causar vários danos à saúde humana e ao ambiente, como a eutrofização dos rios, devido ao excesso de nutrientes. Além disso, pode inibir a oxigenação das células, devido à ingestão de elevado cianeto, ainda presente na mandioca, causando, assim, morte celular por falta de oxigênio (HAMEL, 2011). Em virtude da problemática da manipueira, devido à sua composição, sobretudo de elevada matéria orgânica e cianeto, esse efluente necessita de tratamento adequado.

Dessa forma, esta pesquisa objetiva quantificar quimicamente os principais poluentes de manipueira oriunda de uma indústria produtora de farinha de mandioca, localizada no Oeste Paulista, bem como apresentar os principais métodos de tratamento desse efluente, para que o mesmo possa ser descartado de forma correta em corpos hídricos receptores.

\section{MÉTODOS}

A manipueira utilizada neste estudo é um resíduo líquido proveniente de uma indústria de fabricação de farinhas, localizada no oeste do estado de São Paulo. Nesta indústria, são produzidos diversos tipos de farinha torrada, amarela e normal. A geração de efluentes é dependente do produto e da sua quantidade produzida, o qual passa por tratamento físicoquímico e biológico para posterior lançamento em corpo hídrico receptor.

A amostra de manipueira foi coletada na entrada da estação de tratamento de efluentes do local, ou seja, a manipueira bruta, gerada nos processos produtivos da empresa. Após coleta, o efluente bruto foi caracterizado por meio dos parâmetros químicos de $\mathrm{pH}$, turbidez, demanda química de oxigênio (DQO), demanda bioquímica de oxigênio (DBO), sólidos totais (ST), sólidos totais voláteis (STV), sólidos totais fixos (STF) e cianeto livre, os quais são parâmetros de grande importância, tanto para a caracterização, quanto para o lançamento deste efluente.

$\mathrm{O} \mathrm{pH}$ foi obtido por potenciometria, em pH-metro Sppencer ${ }^{\circledR}$ SP3650-65 (Hipperquímica). A turbidez foi analisada por nefelometria, em turbidímeto Hanna HI93703C. A DBO foi determinada pelo método manométrico, utilizando um sistema Aqualytic AL606, sendo incubadas a 5 dias por $20 \pm 1{ }^{\circ} \mathrm{C}$. Para a determinação da DQO utilizou-se a técnica de colorimetria (método 5220 D) e quantificação das concentrações de ST, STV e STF ocorreram por gravimetria (métodos 2540 B e $2540 \mathrm{E}$ ), ambos segundo o Standard Methods for Examination of Water and Wastewater (AMERICAN PUBLIC HEALTH ASSOCIATION, 1998). O cianeto foi determinado por fotometria, em fotômetro Merck Nova 60 Spectroquant ${ }^{\circledR}$ (método 114561), sendo que a concentração obtida corresponde 
aos cianetos livres $\left(\mathrm{CN}^{-}\right.$e $\left.\mathrm{HCN}\right)$ e de ligações fracas a moderadas.

\section{RESULTADOS E DISCUSSÕES}

$\mathrm{Na}$ Tabela 1 são apresentados os resultados da caracterização química da manipueira, efluente oriundo da produção de farinha de mandioca.

De acordo com esses dados, é possível ter um panorama das características da manipueira. $\mathrm{O} \mathrm{pH}$ do efluente se apresentou ácido, provavelmente devido à presença do ácido cianídrico. Tanto o $\mathrm{pH}$, quanto a turbidez e a concentração de cianeto se apresentaram acima dos limites permitidos para o lançamento deste efluente (BRASIL, 2005, 2011).

Tabela 1. Características químicas da manipueira.

\begin{tabular}{lcc}
\hline \multicolumn{1}{c}{ Parâmetro } & Valores & Limites $^{\mathrm{a}}$ \\
\hline $\mathrm{pH}$ & 4,6 & $5,0-9,0^{(1)}$ \\
Turbidez (UNT) & 1000 & $100^{(2)}$ \\
$\begin{array}{l}\text { Demanda bioquímica de } \\
\text { oxigênio (DBO) }\left(\mathrm{mg} \mathrm{L}^{-1}\right)\end{array}$ & 694 & $5,0^{(2)}$ \\
$\begin{array}{l}\text { Demanda química de } \\
\text { oxigênio (DQO) }\left(\mathrm{mg} \mathrm{L}^{-1}\right)\end{array}$ & 17914 & - \\
$\begin{array}{l}\text { Cianeto }\left(\mathrm{mg} \mathrm{L}^{-1}\right) \\
\text { Sólidos totais (mg L }\end{array}$ & 17,5 & $0,2^{(1)}$ \\
$\begin{array}{l}\text { Sólidos totais voláteis } \\
\text { (STV) (mg L }\end{array}$ & 44500 & - \\
Sólidos totais fixos (STF) & 37100 & - \\
(mg L & & \\
\hline
\end{tabular}

Nota: (a) Limites permitidos para o lançamento, segundo (1) Resolução CONAMA n. 430/2011 (BRASIL, 2011): (2) Resolução CONAMA n. 357/2005 (BRASIL, 2005), referende a rios classe 2.

Fonte: os autores.

Da mesma forma, os sólidos totais, fixos e voláteis foram detectados em concentrações extremamente altas. A coloração da manipueira é influenciada pela presença de sólidos dissolvidos no efluente, conferindo uma cor amarelo forte ao mesmo, enquanto que a turbidez é formada pela contribuição das partículas suspensas, presentes no mesmo. A alta concentração de STF pode indicar a elevada salinidade desse efluente, podendo apresentar efeito inibitório aos microrganismos aquáticos, segundo Contrera (2008).

A matéria orgânica também foi encontrada em elevadas concentrações na manipueira, uma vez que ambos os seus parâmetros, DQO e DBO, se apresentaram bastante altos; sendo que a DBO, único parâmetro de matéria orgânica com limite estabelecido pela legislação, se apresentou acima desse limite permitido, que é de $5,0 \mathrm{mg} \mathrm{L}^{-1}$. A baixa biodegradabilidade, expressa pela relação DQO/DBO indica a característica recalcitrante desse efluente, uma vez que razões maiores que 4,0 indicam, segundo Von Sperling (2014), efluente de elevada fração inerte (não biodegradável), sendo mais indicados, para o seu tratamento, os processos físico-químicos ou avançados. Além disso, essa razão indica a predominância de compostos refratários sobre os biodegradáveis. Todos os parâmetros avaliados evidenciam a necessidade de tratamento adequado da manipueira.

Dentre os diversos processos disponíveis, têm-se os físico-químicos, biológicos e avançados. Cabe ressaltar que a melhor técnica irá depender, principalmente, das características do efluente. Os processos biológicos podem ser anaeróbios, como biodigestores, lagoas anaeróbias, reator anaeróbio de fluxo ascendente (RAFA) e filtro anaeróbio; e os biológicos aeróbios, como lodos ativados, lagoas aeradas e filtros biológicos. Tais processos são indicados para efluentes compostos por substâncias predominantemente biodegradáveis.

As lagoas anaeróbias, apesar de pouco eficiente, é a técnica mais comumente utilizada em fecularias e casas de farinhas; no entanto, esse processo apresenta algumas desvantagens, como a emissão descontrolada de gases e riscos de sobrecargas das lagoas por falta de monitoramento e excesso de efluente (UBALUA, 2007).

Por outro lado, o biodigestor, segundo UBALUA (2007), se apresenta como uma tecnologia mais eficiente, uma vez que o mesmo se mantém energeticamente, aproveitando o resíduo de maneira sustentável e transformandoo em energia, de acordo com NOGUEIRA (1992) o biodigestor tem como finalidade a remoção da matéria orgânica, portanto se dimensionado de maneira minuciosa este retira boa parte da carga orgânica do biodigestão e gera como produto a energia. $O$ tratamento da manipueira por biodigestão normalmente ocorre em duas fases sequenciais, acidogênese e metanogênese, as quais são caracterizadas pela presença das bactérias metanogênicas ou acidogênicas, que decompõe a matéria orgânica em detrimento do $\mathrm{pH}$ do meio. Isso é considerado uma dificuldade, em virtude do custo de implantação desse 
sistema em duas fases ser mais elevado, por necessitar de maior controle das fases e, ainda assim, são predominantes em relação aos biodigestores de fase única; no entanto, o retorno financeiro desse sistema está relacionado diretamente com a produção de biogás que o efluente produz e o investimento aplicado segundo Coldebella (2006).

Dentre os sistemas biológicos aeróbios, destaca-se o Reator Anaeróbico de Fluxo Ascendente (RAFA) (em inglês, Upflow Anaerobic Sludge Blanket - UASB). Esse reator possui, em seu compartimento superior, um decantador e um defletor de gases formados. O efluente é introduzido no fundo do reator, de modo a percorrer em fluxo ascendente, sendo descartado na parte superior do decantador (LEETINGA, G. et al. 1994). Nesse processo, o efluente atravessa uma camada de lodo biológico de alta atividade, permitindo a transformação da matéria orgânica em biogás e, desta maneira, empurra o gás a uma região exclusiva para tal, podendo, assim, ser coletado. Dessa forma, o líquido e os sólidos em suspensão resultantes, se concentram no decantador, localizado na parte inferior do RAFA. Uma característica importante desse reator é que o material orgânico, que fica depositado no decantador, é rico em atividade metanogênica, servindo como ator biológico na degradação, além de se sedimentar facilmente, facilitando a sua retirada para limpeza (LEETINGA, G. et al., 1994).

Dentre os processos biológicos, o tratamento por lagoas de estabilização é uma das técnicas mais aplicadas, devido ao seu baixo custo (KOETZ et al., 1995) e eficiência de remoção dos poluentes biodegradáveis. Segundo Pazirotto (2002), a eficiência da remoção da matéria orgânica nesse sistema é de, aproximadamente, $70 \%$. No entanto, as lagoas biológicas não são eficientes para a redução de poluentes recalcitrantes e de nutrientes, como nitrogênio e fósforo.

O RACoV (Reator Anaeróbico Compartimentado Vertical) também é uma ótima tecnologia para remoção de carga orgânica de efluentes. A configuração deste reator é em forma de câmaras para assimilação de choques ácidos, em relação ao $\mathrm{pH}$ e à alcalinidade total e parcial, segundo Silva et al. (2000). Porém, de acordo com Correia e Bianchi (2008), faz-se necessário corrigir o $\mathrm{pH}$ inicial do efluente para facilitar a estabilização do material orgânico e evitar choques ácidos na fase metanogênica.
Segundo esses autores, dependendo da composição do efluente, é possível obter remoções acima de $90 \%$, em curtos tempos de retenção hidráulica (TRH) e com reduzido espaço de compartimentos, tornando o RACoV um processo vantajoso para degradação de efluentes.

A produção de biogás para queima ou produção de energia é de grande uso no país, sobretudo perante necessidade de uma energia mais limpa e de maior rentabilidade. Existem biorreatores capazes de degradar o efluente e, ainda, permitir a captação dos gases gerados. Isto foi verificado no estudo de Lamaison (2009), utilizando um reator anaeróbio de batelada sequencial (RABS), 2 litros manipueira e TRH de 48 horas, conseguiu obter boa produção de hidrogênio, sendo produzido um volume médio diário de $470 \mathrm{ml}$ de biogás, o qual era constituído de $51,5 \%$ de hidrogênio e o restante de metano.

Para se obter sucesso com o tratamento biológico, os reatores devem ser operados adequadamente, identificando-se com rapidez e segurança os distúrbios no seu desempenho, por meio do monitoramento de seus parâmetros de operação.

Os processos físico-químicos, por sua vez, são mais recomendados para tratamento de efluentes predominantemente compostos por matéria orgânica recalcitrante, com baixa razão DBO/DQO e presença de poluentes refratários, como amônia (AMORIM et al., 2009). Essas técnicas são capazes de remover poluentes recalcitrantes, partículas suspensas, cor, compostos tóxicos, como os metais, e pode ser aplicada de forma única ou como pré ou póstratamento dos efluentes. Dentre os processos físico-químicos mais comuns, destacam-se: coagulação-floculação-sedimentação, remoção de amônia por arraste de ar, precipitação química, adsorção e separação por membranas.

Os processos que envolvem mecanismos físicos dependem da ação da gravidade ou de agentes químicos para a deposição dos sólidos sobrenadantes na parte inferior dos equipamentos. Esses processos podem operar de forma mecanizada, com agitadores de rotação baixa, ou apenas pelo uso da gravidade para que os poluentes, concentrados nos sólidos, decantem. Os métodos de princípios químicos, por sua vez, podem ser realizados por floculadores, os quais podem ou não passar por um processo de decantação, ou por filtros, como a técnica de separação por membranas. No 
entanto, os sistemas com filtração apresentam a desvantagem de limpeza do material filtrante e formação de fouling, diminuindo a sua viabilidade e necessitando de descarte adequado do subproduto gerado (lodo).

Todos os processos apresentados possuem vantagens e desvantagens, os quais devem ser ajustados de modo a se adequar a cada indústria. Portanto, a escolha do método mais adequado para o tratamento da manipueira irá depender, dentre outros fatores, das características e quantidade do efluente; da eficiência a ser atingida pelos processos de tratamento, a fim de atender aos requisitos legais; da disponibilidade financeira e de espaço; e dos custos de implantação e operação do sistema escolhido.

\section{CONSIDERAÇÕES FINAIS}

A caracterização química da manipueira, efluente originário da produção de farinha de mandioca, mostrou a grande complexidade desse resíduo, principalmente devido às suas altas concentrações de matéria orgânica, prioritariamente recalcitrante, e de ácido cianídrico (indicado pelo parâmetro cianeto).

A partir dos métodos de tratamento propostos, cada indústria deve avaliar a melhor técnica com base, principalmente, nas características da manipueira gerada em seus processos, bem como nos aspectos econômicos, ambientais e legais. Muito provavelmente, um único processo não será suficiente para a degradação completa da manipueira aqui analisada, necessitando-se, assim, de uma combinação de técnicas. Cabe ressaltar, ainda, que uma maior avaliação físico-química e biológica deve ser realizada no efluente estudado, visando implantar o processo mais adequado e que atinja os padrões estabelecidos pelas legislações ambientais.

\section{REFERÊNCIAS}

AMERICAN PUBLIC HEALTH ASSOCIATION - APHA. Standard Methods for Examination of Water and Wastewater. 20. ed. Washington: APHA, 1998.

AMORIM, A. K. B. et al. Tratamento físicoquímico de lixiviados: estudos em escala de bancada com precipitação química, coagulação/floculação, adsorção com carvão ativado e reagente de fenton. In: GOMES, L. P. (Coord.). Resíduos Sólidos: Estudos de caracterização e tratabilidade de lixiviados de aterros sanitários para as condições brasileiras. Projeto PROSAB. Rio de Janeiro: ABES, 2009.

BERNI, M. D.; BAJAY, S. V. Geração de energia e a digestão anaeróbia no tratamento de efluentes: estudo-de-caso na indústria de papel. In: ENCONTRO DE ENERGIA NO MEIO RURAL, 3, 2000, Campinas. Anais... Campinas: UNICAMP, 2000.

COLDEBELLA, A. et al. Viabilidade da cogeração de energia elétrica com biogás da bonivocultura de leite. In: ENCONTRO DE ENERGIA NO MEIO RURAL, 6, 2006. Campinas. Anais... Campinas: Unicamp, 2006.

CONTRERA, R. C. Tratamento de lixiviados de aterro sanitário em sistemas de reatores anaeróbio e aeróbio operados em batelada sequencial. 2008. Tese (Doutorado) Universidade de São Paulo, São Carlos. https://doi.org/10.11606/T.18.2008.tde15022009-221141

CORREIA G. T.; BIANCHI V. L. D. Tratamento biológico de água residuária da produção de farinha de mandioca utilizando reator anaeróbico compartimentado vertical (RACOV). Ciências Exatas e Tecnológicas, v. 29, n. 2, p. 159-166, jul./dez. 2008. https://doi.org/10.5433/16790375.2008v29n2p159

HACH COMPANY. DR 2800 Spectrophotometer procedures manual. USA, 2007.

HAMEL, J. A. Review of acute cyanide poisoning with a treatment update. Critical Care Nurse, v. 31, n. 1, p. 72-82, 2011. https://doi.org/10.4037/ccn2011799

INSTITUTO BRASILEIRO DE GEOGRÁFICA E ESTATÍSTICA - IBGE. Levantamento sistemático da produção agrícola. 2010. 120p.

JUBB, K. V. F.; HUXTABLE, C. R. The nervous system. In: JUBB, K. V. F., KENNEDY, P. C.; PALMER, N. (Ed.) Pathology of domestic animals, v.1, 4. ed. San Diego: Academic Press, 1993. https://doi.org/10.1016/B978-0-08-0571331.50011-4 
KOETZ, P. R.; FARIA, O. L. V.; NUNES, W. A. Tratamento de efluentes homogeneizados de curtume por digestão anaeróbia em reatores de fluxo ascendente. Revista Brasileira de Agrociência, v.1, n.1, p.23-29, 1995.

LAMAISON, F. C. Aplicação da água residuária do processamento da mandioca como substrato para a produção de hidrogênio por processo fermentativo. 2009. Dissertação (Mestrado) Universidade Federal de Santa Catarina, Florianópolis.

LEETINGA, G. et al. Anaerobic sewage treatment: a practical guide for regions with hot climates. Chichester, U.K.: John Wiley \& Sons, 1994, 226 p.

PARIZOTTO, A. A. Minimização de custos econômicos e ambientais pelo uso de lagoas de sedimentação no tratamento de despejos de fecularias. Informe Gepec, v.6, n. 2, p. 7-16, 2002.

SERVIÇO BRASILEIRO DE APOIO ÀS MICRO E PEQUENAS EMPRESAS - SEBRAE. Mandioca (farinha e fécula): Informações de mercado sobre a mandioca (farinha e fécula). 2012, 34 p. Disponível em: <http://www.bibliotecas.sebrae.com.br/chronus/ ARQUIVOS_CHRONUS/bds/bds.nsf/5936f2d444b a1079c3aca02800150259/\$File/4247.pdf>.

Acesso: 08 maios 2018.

SILVA, G. H. R. et al. Comportamento de um reator compartimentado híbrido submetido a um período de operação precária: estabilidade do sistema. In: CONGRESSO INTERAMERICANO DE ENGENHARIA SANITÁRIA E AMBIENTAL, 27, 2000, Porto Alegre. Anais... Porto Alegre: AIDIS, 2000.

UBALUA, A. O. Cassava waste treatment options and value addition alternatives. African Journal of Biotechnology, v. 6, p. 2065-2073, 2007. https://doi.org/10.5897/AJB2007.000-2319

VON SPERLING, M. Introdução à qualidade das águas e o tratamento de esgotos. 4. ed. Belo Horizonte: Editora UFMG, 2014. 